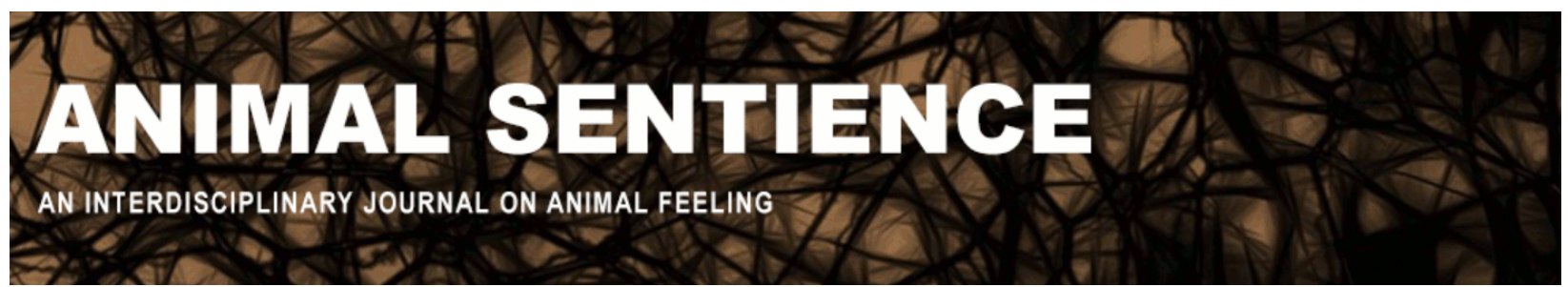

Vallortigara, Giorgio (2017) Sentience does not require "higher" cognition. Animal Sentience 17(6)

DOI: $10.51291 / 2377-7478.1226$

Date of submission: $2017-10-15$

Date of acceptance: 2017-10-17

(c)

This article has appeared in the journal Animal

Sentience, a peer-reviewed journal on animal

cognition and feeling. It has been made open access,

free for all, by WellBeing International and deposited

in the WBI Studies Repository. For more information,

please contact

wbisr-info@wellbeingintl.org.

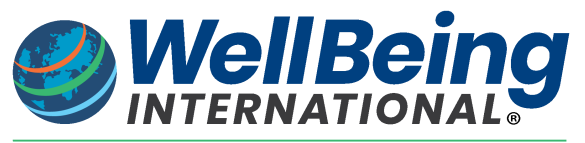

SOLUTIONS FOR PEOPLE, ANIMALS AND ENVIRONMENT 


\title{
Sentience does not require "higher" cognition
}

Commentary on Marino on Thinking Chickens

\author{
Giorgio Vallortigara \\ Centre for Mind/Brain Sciences \\ University of Trento, Italy
}

\begin{abstract}
I agree with Marino (2017a,b) that the cognitive capacities of chickens are likely to be the same as those of many others vertebrates. Also, data collected in the young of this precocial species provide rich information about how much cognition can be pre-wired and predisposed in the brain. However, evidence of advanced cognition - in chickens or any other organism - says little about sentience (i.e., feeling). We do not deny sentience in human beings who, because of cognitive deficits, would be incapable of exhibiting some of the cognitive feats of chickens. Moreover, complex problem solving, such as transitive inference, which has been reported in chickens, can be observed even in the absence of any accompanying conscious experience in humans.
\end{abstract}

Giorgio Vallortigara, professor of Neuroscience at the Centre for Mind/Brain Sciences of the University of Trento, Italy, studies space, number and object cognition, and brain asymmetry in a comparative and evolutionary perspective. The author of more than 250 scientific papers on these topics, he was the recipient of several awards, including the Geoffroy Saint Hilaire Prize for Ethology (France) and a Doctor Rerum Naturalium Honoris Causa for outstanding achievements in the field of psychobiology (Ruhr University, Germany). r.unitn.it/en/cimec/abc

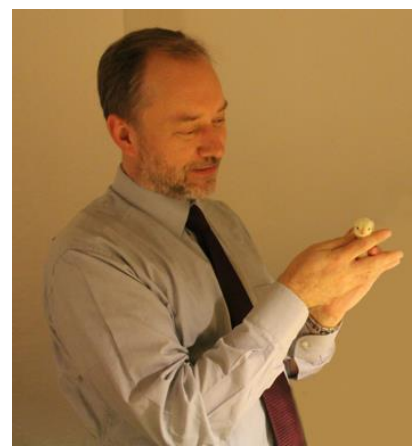

In a revealing piece in New Scientist (Lawler, 2015a) and a beautiful book (Lawler, 2015b), science journalist Andrew Lawler discussed the possible consequences for humans of the sudden disappearance of some domesticated species. If cats and dogs were to disappear tomorrow, it would be tragic for the owners of these most beloved creatures; if beef cattle disappeared, economic crisis could be expected in some countries (e.g., USA, Argentina). All of this would be upsetting on psychological and economic grounds, but plausibly we would survive. What about the disappearance of chickens because of, say, bird flu? Lawler argued convincingly that with the sudden disappearance of chickens, the human species could be in big trouble. There are an estimated 22 billion chickens in the world at present, providing one-third of the world's meat supply. In Lawler's words:

"(...) For every person, three chickens are alive and clucking today. Humans gobble down almost 100 million tonnes of chicken meat and over 1 trillion eggs annually." 
These numbers show how much chickens are exploited by humans: most exploited commercially and little respected cognitively. We must thus applaud Lori Marino's (2017a,b) timely review of the mental capabilities of chickens.

Actually, I totally agree with Marino that there is nothing special in chickens' cognitive abilities: they are not different from those exhibited by others vertebrates. There is, however, something that I would like to add to Marino's review, to reinforce her position but also to put research on chickens' cognition in an historical perspective within ethology, comparative psychology and neurobiology.

My brief historical note is just to show that an appreciation of chickens' cognition was apparent in science, though admittedly sparse in the scientific literature, well before the recent important advances in our understanding of pallial evolution in the avian and mammalian brains (reviews in Jarvis, 2009; Güntürkün and Bugnyar, 2016). Clearly, however, these studies have not had an impact on a large audience, particularly non-specialists. They were aimed at specific scientific problems (e.g., memory, early knowledge, brain asymmetry). The role played by chickens, although crucial, appeared mostly instrumental.

I would also like to comment on the kinds of conclusions we should draw about sentience from the evidence of advanced cognitive abilities for sentience in chickens and others creatures.

\section{The legacy of research on chick(ens)}

Even though comparative psychologists have for several (sometimes wrong) reasons, chosen rats and pigeons as the prototypical animal models among, respectively, mammals and birds, there has been (and still is) a tradition of research that instead favored the use of young chicks (and ducklings) to investigate various aspects of cognition and its brain bases.

Young precocial nidifugous birds, such as ducklings and domestic chicks, were ideal species for the study of early learning, in particular imprinting (for reviews of the advantages of studying precocial species see Versace, 2017; Versace and Vallortigara, 2015). Douglas Spalding, the pioneer of ethology, first discovered imprinting in domestic chicks, dubbing it "imperfect instinct" (Spalding, 1873). Imprinting is still a very active area of research with important implications for the study of recognition memory and exposure learning (for recent reviews see Horn, 2004; McCabe, 2013).

Associated with the phenomenon of imprinting are also the topics of sensitive periods and biological predispositions to imprinting (so-called "imprintability," see also Bateson, 2011). Toshiya Matsushima and Koichi Homma in Japan (Yamaguchi et al., 2012) have recently provided an important breakthrough with evidence that sensitive periods in chicks can be re-opened by thyroid hormone $\mathrm{T}_{3}-$ a finding with deep implications also for human health (Yamaguchi et al., 2012). Biological predispositions to attend to animated objects (and thus to imprint on them) have revealed surprising links with various aspects of early cognition in human newborns (review in Vallortigara, 2012a,b). Topics such as non-learned preferences for face-like stimuli (Johnson, 2005; Johnson and Horn, 1988; Johnson and Morton, 1991; Rosa-Salva et al., 2010; 2011), biological motion (Vallortigara et al., 2005; Vallortigara and Regolin, 2006; Johnson, 2006; RosaSalva et al., 2016; Versace et al., 2017a), causal agency (Mascalzoni et al., 2010), and acoustic consonant intervals (Chiandetti and Vallortigara, 2011a) in newly-hatched chicks have been guided by research on humans (reviews in Di Giorgio et al., 2016b; Rosa Salva et al., 2015) in a 
complex interdisciplinary interplay between ethology (Versace et al., 2017), neurobiology (Lorenzi et al., 2017) and developmental psychology (Di Giorgio et al., 2017; Mascalzoni et al., 2013; Simion et al., 2008). Such an interdisciplinary endeavor recently provided evidence that the absence of the predisposition to attend to the animacy cues revealed in chick research could be useful in early diagnosis of human neurodevelopmental disorders such as autism (Di Giorgio et al., 2016a).

There is also another historical root to chicks' cognition research, however, different from that of classical ethology and early learning. In Europe in the years between the two World wars, some zoologists and experimental psychologists in the new school of Gestalt psychology did innovative research on animal cognition. Several of them used chicks or adult chickens as subjects. For example, Kohler did research on relational (brightness) perception in chickens (reported in Werner, 1940), Ducker on optical illusions (Ducker, 1966), and Revesz (quoted in Katz, 1933) on number cognition. Mario Zanforlin - whom Marino mentions as the first scientist documenting the perception of Kanizsa's subjective contours in chicks (Zanforlin, 1981) belonged to this tradition, linking it with that of classical ethology via Aubrey Manning in Edinburgh. (I did the same, actually, combining my own original Gestalt background with Mario with British ethology and neurobiology thanks to the mentorship of Richard Andrew at Sussex University.)

Such a tradition of comparative research on visual illusions and perceptual organization (e.g., Vallortigara and Tommasi, 2001; Forkman and Vallortigara, 1999), inspired by Gaetano Kanizsa himself (e.g., Kanizsa et al., 1993), is still alive in the universities of North-East of Italy such as Padua, Trento and Trieste, and uses chicks as one of its preferred models (see Vallortigara, 2004; 2006). There have been followers also in the US, particularly on whether some perceptual phenomena, such as the perception of light-from-above, are learned or innate (Hershberger, 1970). This work continues today with interest in using chicks as model systems by perceptual psychologists such as Alan Gilchrist, who study perceptual constancy (Gilchrist et al., 2017). Studies on chicks' cognition, with particular reference to anticipation of forthcoming events, in relation to the quality/quantity and the temporal proximity of rewards, are also conducted in Japan (Matsushima et al., 2003).

Young chicks have also been an extraordinary model in the hands of researchers such as Art Cherkin (1972), Steven Rose (1993) and Richard Andrew (1991a) to investigate the neural bases of memory and memory consolidation using the very simple task of passive aversion after a single experience of pecking a bitter tasting pellet. I would like to mention in this regard the extraordinary, but little known, finding of Richard Andrew that chicks (perhaps like others vertebrates, including humans), show cyclically recurring episodes of successful retrieval in this task, with cycle periods that differ in the two hemispheres: coincidence of retrieval episodes in both hemispheres seems to allow exchanges of information between different traces maintained by the two hemispheres (Andrew, 1991b).

The different functional specialization of the two hemispheres, brain lateralization, is a phenomenon that was until recently thought to be unique to human beings (for reviews see Vallortigara and Rogers, 2005; Rogers and Vallortigara, 2015; Vallortigara and Versace, 2017). Chickens, together with canaries (Nottebohm, 1971), were the first non-human animals in which brain asymmetry was observed. Lesley Rogers, who was the first to observe lateralization of function in the chicken's forebrain (Rogers and Anson, 1979), also discovered that brain 
asymmetry depends in part on asymmetric light stimulation occurring in the embryo (Rogers, 1982). Rogers's studies in chicks opened the way to a huge variety of research on other animal models of the environmental and genetic determinants of brain asymmetry (Rogers, 2014; Rogers et al., 2013; and see also Rogers, 2017, commentary on Marino's paper).

Turning to behavior, it is noteworthy that imprinting has been used as a tool to investigate early knowledge, taking advantage of combining rigorous control of past experience (both in ovo and soon after hatching) with the possibility of testing very sophisticated cognitive tasks thanks to the relative advanced state of motor and sensory development in these precocial animals. Using such a tool, naïve physics understanding (Chiandetti and Vallortigara, 2011), Euclidian geometry (Chiandetti et al., 2014) and, as stressed in Marino's review, number cognition (reviews in Vallortigara, 2017a,b) have been documented in newborn chicks.

More recently, imprinting has been used in young chicks and ducklings to study abstract thought, such as the concept of same/different (Versace et al., 2006; 2017b; Martinho and Kacelnik, 2016) and statistical learning (Santolin et al., 2016). Similarities but also differences from the early cognition of humans have been observed (Versace et al., 2016) - the latter being no less important to a full understanding of the evolution of the mind.

\section{Implications for sentience}

Thus, we can only be grateful to Lori Marino for attracting the attention of a large audience to the cognitive abilities of chickens. I must confess, however, that I would be skeptical as to whether this evidence could be of any help with respect to the issue of animal sentience. I believe sentience - which I interpret as the capacity to have felt experience - has little to do with advanced cognition. (I suspect that it dates back to early metazoans - and can be present in creatures with much simpler brains than those of chickens - but this is of course a topic for another commentary or a target article in Animal Sentience; cf. Key, 2016; Klein \& Barron, 2016; Mallatt \& Feinberg, 2016; Woodruff, 2017).

Indeed, we have no difficulty in attributing a capacity to experience something even to members of our own species who, because of some disease, are severely handicapped in their cognition; some of them even possibly less cognitively gifted than newborn chicks.

It is also important to note that there is evidence that sophisticated cognitive feats may be accomplished by human subjects without any explicit conscious representation. Consider transitive inference, which was mentioned in Marino's target article. This has been traditionally considered a hallmark of human cognition, yet it has been documented in a variety of animals, including pigeons (Fersen et al., 1991) and chicks (Daisley et al., 2010). Does this prove that chicks are conscious? Not at all, for Sieman and Delius (1993) have shown that some human subjects tested with the same kinds of transitive inference tasks used with birds and other non-human animals are capable of providing a correct solution without being aware of it, just claiming that they are "guessing" (as in a sort of cognitive version of "blindsight," Pöppel et al., 1973; Weiskrantz, 1986). In Sieman and Delius's words:

"The result worth emphasizing is that almost half (46.7\%) of the subjects who responded transitively at much better than chance level were completely unable to report verbally how they 
had achieved such excellent performance. This demonstrates that humans can behave according to deductive rules implicitly without being consciously aware of them."

This is of course not to deny conscious experience in non-human animals - just to stress that we cannot easily infer it from possession of allegedly "higher" cognition.

Although I agree with Marino that we need to know more about chicken cognition in naturalistic settings, I would not recommend to limit research on chicks and chickens to noninvasive procedures only. We have learned a lot about how the brain works thanks to these creatures, on such crucial topics as memory consolidation, brain asymmetry, critical periods and biological predispositions to social life - and the outcomes of this research are as important for human health as they are for the health of others animal (including chickens). Of course, all this research on chickens (cognitive and neurobiological), as well as on any other non-human animal species, should be closely scrutinized and approved by ethical committees. (The current standards of the European Community are, in my opinion, very high in this regard.) Even more important to me, research should also be guided by the ethical principles of scientists themselves. But this should be valid for chickens exactly as for any other animal; they all deserve our respect and gratitude.

\section{References}

Andrew, R.J. (Ed.). (1991a). Neural and behavioral plasticity. The use of the chick as a model, ed. R. J. Andrew, p. 570, Oxford University Press.

Andrew, R.J. (1991b). Cyclicity in memory formation. In Neural and behavioral plasticity. The use of the chick as a model, ed. R. J. Andrew, pp. 476-502. Oxford University Press.

Bateson, P. (2011). Plasticity, robustness, development and evolution. Cambridge University Press.

Bolhuis, J.J. (1991). Mechanisms of avian imprinting: A review. Biological Reviews, 66, 303-345.

Cherkin, A. (1972). Retrograde amnesia in the chick: Resistance to the reminder effect. Physiology and Behavior, 8, 949-955.

Chiandetti, C., \& Vallortigara, G. (2011a). Chicks like consonant music. Psychological Science, 22, 1270-1273.

Chiandetti, C., \& Vallortigara, G. (2011b). Intuitive physical reasoning about occluded objects by inexperienced chicks. Proceedings of the Royal Society of London, B, 278, 2621-2627.

Chiandetti, C., Spelke, E.S., \& Vallortigara, G. (2014). Inexperienced newborn chicks use geometry to spontaneously reorient to an artificial social partner. Developmental Science, 18, 972-978. doi: 10.1111/desc.12277

Daisley, J.N., Vallortigara, G., \& Regolin, L. (2010). Logic in an asymmetrical (social) brain: Transitive inference in the young domestic chick. Social Neuroscience, 5, 309-319.

Di Giorgio, E., Frasnelli, E., Rosa Salva, O., Scattoni, M.L., Puopolo, M., Tosoni, D., Simion, F., \& Vallortigara, G. (2016a). Difference in visual social predispositions between newborns at low- and high-risk for autism. Scientific Reports, 6, 26395. doi: 10.1038/srep26395. 
Di Giorgio, E., Loveland, J.L., Mayer, U., Rosa-Salva, O., Versace, E., \& Vallortigara, G. (2016b). Filial responses as predisposed and learned preferences: Early attachment in chicks and babies. Behavioural Brain Research, 325, 90-104.

Di Giorgio, E., Lunghi, M., Simion, F., \& Vallortigara, G. (2017). Visual cues of motion that trigger animacy perception at birth: The case of self-propulsion. Developmental Science, 20, e12394. doi:10.1111/desc.12394

Ducker, G. (1966). Optical illusions in vertebrates. Zeitschrift für Tierpsychologie, 23(4), 452-496.

Fersen, L. von, Wynne, C. D. L., Delius, J. D., \& Staddon, J. E. R. (1991). Transitive inference formation in pigeons. Journal of Experimental Psychology: Animal Behavior Processes, 17, 334-341.

Forkman, B., \& Vallortigara, G. (1999). Minimization of modal contours: An essential cross species strategy in disambiguating relative depth. Animal Cognition, 4: 181-185.

Gilchrist, A., Jevtic, K., Altamirano, C., Peyvandi, S., \& Vallortigara, G. (2017). Newborn chicks show lightness constancy despite a change in either illumination or background. $40^{\text {th }}$ European Conference on Visual Perception, 27-31 August, Berlin, Germany.

Güntürkün, O., \& Bugnyar, T. (2016). Cognition without cortex: Trends in cognitive sciences. doi: $10.1016 / j . t i c s .2016 .02 .001$

Hershberger, W. (1970). Attached-shadow orientation perceived as depth by chickens reared in an environment illuminated from below. Journal of Comparative and Physiological Psychology, 73(3), 407-411. http://dx.doi.org/10.1037/h0030223

Horn, G. (2004). Pathways of the past: the imprint of memory. Nature Reviews Neuroscience, 5, 108-120.

Jarvis, E. E. (2009). Bird brain: Evolution. In Encyclopedia of neuroscience. Squire, L.R. (ed.), volume 2, pp. 209-215. Oxford: Academic Press.

Johnson, M.H. (2005). Subcortical face processing. Nature Reviews in Neuroscience, 6, 766-774. Johnson, M.H. (2006). Biological motion: A perceptual life detector? Current Biology, 16, R376R377.

Johnson, M.H., \& Horn, G. (1988). Development of filial preferences in the dark reared chick. Animal Behaviour, 36, 675-683.

Johnson, M.H., \& Morton, J. (1991). Biology and cognitive development: The case of face recognition. Blackwell, Oxford.

Kanizsa, G., Renzi, P., Conte, S., Compostela, C., \& Guerani, L. (1993). Amodal completion in mouse vision. Perception, 22, 713-721.

Katz, D. (1937). Animals and men. London: Longmans Green.

Key, B. (2016). Why fish do not feel pain. Animal Sentience 3(1).

Klein, C., \& Barron, A. B. (2016). Insects have the capacity for subjective experience. Animal Sentience 9(1).

Lawler, A. (2015a). Clucking hell: The nightmare world without chickens. New Scientist, 19 March.

Lawler, A. (2015b). Why did the chicken cross the world? Gerald Duckworth \& Co Ltd, New York.

Lorenz, K. (1935). Der Kumpan in der Umwelt des Vogels. Journal fur Ornithologie, 83, 137-213; 289-413. 
Lorenzi, E., Mayer, U., Rosa-Salva, O., \& Vallortigara, G. (2017). Dynamic features of animate motion activate septal and preoptic areas in visually naïve chicks (Gallus gallus). Neuroscience, 354, 54-68.

Mallatt, J. \& Feinberg, T. (2016). Insect consciousness: Fine-tuning the hypothesis. Animal Sentience 9(10).

Marino, L. (2017a). The inconvenient truth about thinking chickens. Animal Sentience 17(1).

Marino, L. (2017b). Thinking chickens: A literature review of cognition, emotion, and behavior in the domestic chicken. Animal Cognition, 20(2), 127-141.

Martinho, A., \& Kacelnik, A. (2016). Ducklings imprint on the relational concept of "same or different". Science, 80, 286-288.

Matsushima, T., Izawa, E., Aoki, N., \& Yanagihara, S. (2003). The mind through chick eyes: Memory, cognition and anticipation. Zoological Science, 20(4), 395-408.

McCabe, B.J. (2013). Imprinting. Wiley Interdisciplinary Reviews: Cognitive Science, 4, 375-390.

Nottebohm, F. (1971). Neural lateralization of vocal control in a passerine bird. Journal of Experimental Zoology, 177(2), 229-261.

Pöppel, E., Held, R., \& Frost, D. (1973). Residual visual function after brain wounds involving the central visual pathways in man. Nature, 243, 295-296.

Rogers, L.J. (1982). Light experience and asymmetry of brain function in chickens. Nature, 297, 223-225.

Rogers, L.J. (2014). Asymmetry of brain and behavior in animals: Its development, function, and human relevance. Genesis, 52(6), 555-571. doi: 10.1002/dvg.22741

Rogers, L.J. (2017). Chickens' brains, like ours, are lateralized. Animal Sentience 17(3).

Rogers L.J., \& Anson, J.M. (1979). Lateralisation of function in the chicken fore-brain. Pharmacology, Biochemistry and Behavior, 10, 679-686.

Rogers, L.J., \& Vallortigara, G. (2015). When and why did brains break symmetry? Symmetry, 7, 2181-2194.

Rogers, L.J., Vallortigara, G., \& Andrew, R.J. (2013). Divided brains. Cambridge University Press, New York.

Rosa Salva, O., Mayer, U., \& Vallortigara, G. (2015). Roots of a social brain: Developmental models of emerging animacy-detection mechanisms. Neuroscience and Biobehavioral Reviews, 50: 150-168.

Rosa-Salva, O., Farroni, T., Regolin, L., Vallortigara, G., \& Johnson, M.H. (2011). The evolution of social orienting: Evidence from chicks (Gallus gallus) and human newborns. PLoS ONE, 6(4), e18802.

Rosa-Salva, O., Grassi, M., Lorenzi, E., Regolin, L., \& Vallortigara, G. (2016). Spontaneous preference for visual cues of animacy in naïve domestic chicks: The case of speed changes. Cognition, Dec.; 157, 49-60. doi: 10.1016/j.cognition.2016.08.014. Epub 2016, Sep. 2.

Rosa-Salva, O., Regolin, L., \& Vallortigara, G. (2010). Faces are special for chicks: Evidence for inborn domain-specific mechanisms underlying spontaneous preferences for face-like stimuli. Developmental Science, 13, 565-577.

Rose, S.P.R. (1993). The making of memory: From molecules to mind. Bantam, London, 355 pp.

Santolin, C., Rosa-Salva, O., Vallortigara, G., \& Regolin, L. (2016). Unsupervised statistical learning in newly-hatched chicks. Current Biology, 26, 1218-1220. 
Siemann, M., \& Delius, J.D. (1993). Implicit deductive responding in humans. Naturwissenschaften, 80, 8, 364-366.

Spalding, D.A. (1873). Instinct, with original observations on young animals. Macmilan's Magazine, 27, 282-293.

Vallortigara, G. (2004). Visual cognition and representation in birds and primates. In Vertebrate comparative cognition: Are primates superior to non-primates? (L.J. Rogers \& G. Kaplan, eds.), pp. 57-94, New York, Kluwer Academic/Plenum Publishers.

Vallortigara, G. (2006). The cognitive chicken: Visual and spatial cognition in a non-mammalian brain. In Comparative cognition: Experimental explorations of animal intelligence (E.A. Wasserman \& T.R. Zentall, eds.), pp. 41-58. Oxford University Press, Oxford, U.K.

Vallortigara, G. (2012a). Core knowledge of object, number, and geometry: A comparative and neural approach. Cognitive Neuropsychology, 29(1-2), 213-236. https://doi.org/10.1080/02643294.2012.654772

Vallortigara, G. (2012b). Aristotle and the chicken: Animacy and the origins of beliefs. In The theory of evolution and its impact (A. Fasolo, ed.), pp. 189-200, Springer, New York.

Vallortigara, G. (2017a). An animal's sense of number. In The nature and development of mathematics. Cross disciplinary perspective on cognition, learning and culture (Adams, J.W., Barmby P., \& Mesoudi, A., eds.), pp. 43-65, Routledge, New York.

Vallortigara, G. (2017b). Comparative cognition of number and space: The case of geometry and of the mental number line. Philosophical Transactions of the Royal Society $B$, in press.

Vallortigara, G., \& Regolin, L. (2006). Gravity bias in the interpretation of biological motion by inexperienced chicks. Current Biology, 16: 279-280.

Vallortigara, G., \& Rogers, L.J. (2005). Survival with an asymmetrical brain: Advantages and disadvantages of cerebral lateralization. Behavioral and Brain Sciences, 28, 575-589.

Vallortigara, G., \& Tommasi, L. (2001). Minimization of modal contours: An instance of an evolutionary internalized geometric regularity? Brain and Behavioral Sciences, 24: 706-707.

Vallortigara, G., \& Versace, E. (2017). Laterality at the neural, cognitive, and behavioral levels. In APA handbook of comparative psychology: Vol. 1. Basic concepts, methods, neural substrate, and behavior, J. Call (Editor-in-Chief), pp. 557-577, American Psychological Association, Washington DC.

Vallortigara, G., Regolin, L., \& Marconato, F. (2005). Visually inexperienced chicks exhibit a spontaneous preference for biological motion patterns. PLoS Biology, 3(7), 1312-1316 (e208).

Versace, E. (2017). Precocial. In J. Vonk \& T. Shackelford (eds.), Encyclopedia of animal cognition and behavior. Springer International Publishing. https://doi.org/10.1007/978-3-319-478296 459-1

Versace, E., \& Vallortigara, G. (2015). Origins of knowledge: Insights from precocial species. Frontiers in Behavioral Neuroscience, 9, 338. doi: 10.3389/fnbeh.2015.00338

Versace, E., Fracasso, I., Baldan, G., Dalle Zotte, A., \& Vallortigara, G. (2017). Newborn chicks show inherited variability in early social predispositions for hen-like stimuli. Scientific Reports, 7, 40296. doi: 10.1038/srep40296

Versace, E., Regolin, L., \& Vallortigara, G. (2006). Emergence of grammar as revealed by visual imprinting in newly-hatched chicks. The Evolution of Language. Proceedings of the 6th International Conference. pp. 457-458. 
Versace, E., Schill, J., Nencini, A.M., \& Vallortigara, G. (2016). Naïve chicks prefer hollow objects. PLOS ONE, 11(11), e0166425.

Versace, E., Spierings, M.J., Caffini, M., ten Cate, C., \& Vallortigara, G. (2017). Spontaneous generalization of abstract multimodal patterns in young domestic chicks. Animal Cognition, 20, 521-529. doi: 10.1007/s10071-017-1079-5

Weiskrantz, L. (1986). Blindsight. A case study and implications, London: Oxford University Press.

Werner, H. (1940). Comparative psychology of mental development. New York-Chicago-Los Angeles, p. $216 \mathrm{f}$.

Woodruff, M. L. (2017) Consciousness in teleosts: There is something it feels like to be a fish. Animal Sentience 13(1).

Yamaguchi, S., Aoki, N., Kitajima, T., likubo, E., Katagiri, S., Matsushima, T., \& Homma, K.J. (2012). Thyroid hormone determines the start of the sensitive period of imprinting and primes later learning. Nature Communications, 3, 1081. doi: 10.1038/ncomms2088

Zanforlin, M. (1981). Visual perception of complex forms (anomalous surfaces) in chicks. Italian Journal of Psychology, 8, 1-16. 